أثر رأس المال الفكري على الأداء الفردي وإدارة المعرفة بين خبراء الإششاد الزراعي في الوطن العربي

$$
\text { أحمد محمد دياب '، وهند مختار دياب' }
$$

إحصائيًا من الفروض الثلاثون للدراسة، وأخيرًا خلصت الدراسة

$$
\text { إلى بعض الإستنتاجات وقدمت بعض التوصيات. }
$$

الكلمات المفتاحية: رأس المال الفكري، الأداء الفردي، إدارة

$$
\text { المعرفة، الإرشاد الزراعي، الوطن العربي. }
$$

\section{المقدمة و الإطار النظري}

هناك عدد من التغيرات التي حدث في سياق التتمية الزراعية والتي بمقتضاها يجب إعادة النظر في كيفية حدوث الإبتكار في القطاع الزراعي، منها تطور بيئة الإنتاج والتجارة والاستهلاك لمنتجات الزراعية والزراعة بصورة دينامية وبطرق غير متوقعة، والمشاركة الفعالة من القطاع الخاص في إنتاج ونشر المعارف والمعلومات والتكنولوجيا، وزيادة

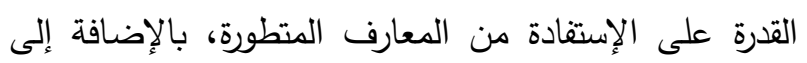
التغير الملحوظ في البناء المعرفي للقطاع الزراعي ( World .(Bank, 2007 \& Rajalahti et al., 2008 وإستجابةً لتلك التغيرات وجب على المنظمات - ومن بينها الإرشاد الزراعي - أن تغير مناهجها الاقتصادية من وجن

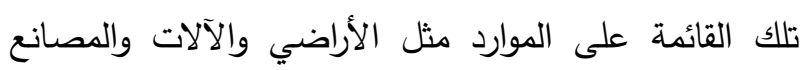
والمواد الخام والقوى العاملة إلى أخرى جديدة على أساس المعرفة وخلق القيمة الاقتصادية من خلال الاستفادة من المعرفة، فالمعرفة باتت تعتبر خاصية رئيسية وأصل قيّم يمثل مثل قاعدة التطوير المستمر ومفتاح الميزة التتافية الدائمة للمنظمات (Bhatt, et al., 2010; Allameh, et al., 2011). ومع تحول الزراعة إلى صناعة كثيفة المعرفة، حيث يحتاج تتضمن المعرفة المالية والمناخية والتقنية والتتظيمية لإدارة

\section{الملخص العربى}

يستهاف البحث الحالي: 1) قياس رأس المالي الفكري بين المبحوثين من خبراء الإرشاد الزراعي في الوطن العربي بإستخدام

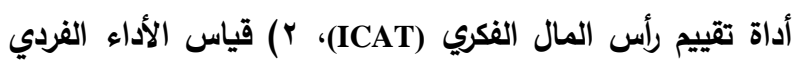
لخبراء الإرشاد الزراعي في الوطن العربي، وبم) قياس إدارة

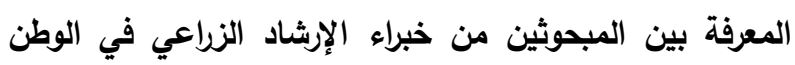

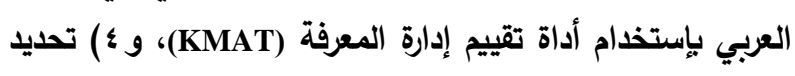
أثر رأس المال الفكري على أداء خبراء الإششاد الزراعي في الوطن العربي، وه) تحديد أثر رأس المال الفكري على إدارة المعرفة بين خبراء الإشاد الزراعي في الوطن العزبي. وقد تم

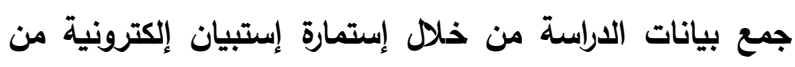

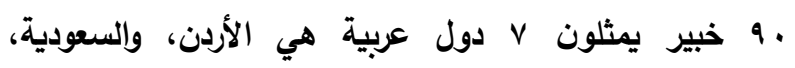
والسودان، والعراق، واليمن، وسوريا، ومصر، وذلك خلد شهر

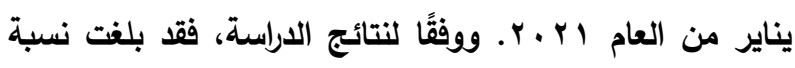
المتوسط الحسابي لكل من رأس المال الفكري ومستوى أداء

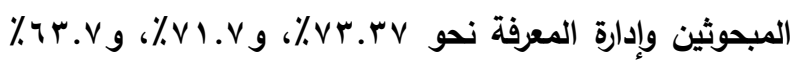
من إجمالي درجات كل مقياس على الترتيب. كما توصلت الدراسة إلى وجود علاقة ارتباطية معنوية على المستوى الاحتمالي ا ... بين الدرجات المعبرة عن جميع محاور رأس المال الفكري

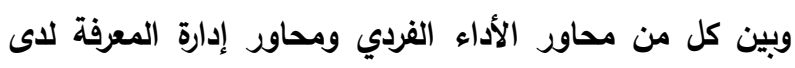
المبحوثين، كما أوضحت النتائج إلى أن كل من رأس المال

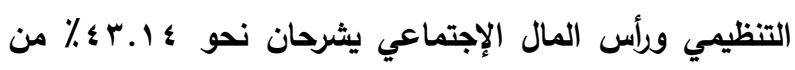
التباين الكلي في درجة الأداء الفردي للمبحوثين، في حين أن كل

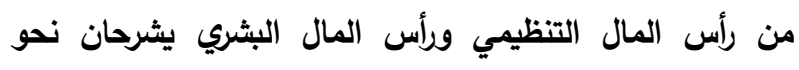

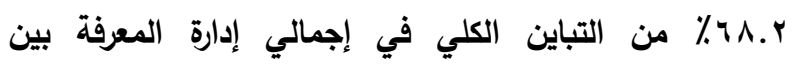

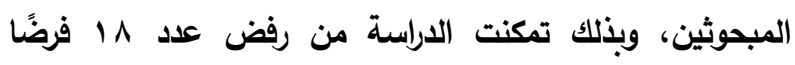

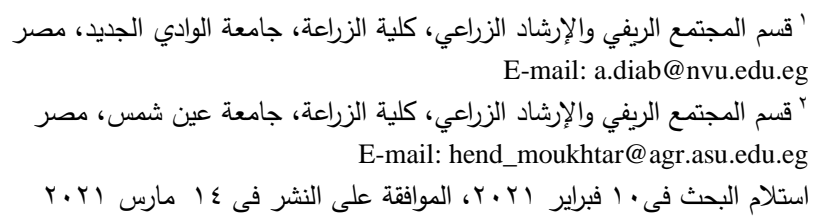


المعارف الضمنية التراكمية للأفراد وكفاءاتهم وخبراتهم ومهاراتهم وإبداعاتهم ومواهبهم.

- رأس المال التظيمي Organizational Capital والمعروف أيضًا باسم رأس المال الهيكلي Structural Capital ويشير إلى المعرفة الواضحة المضمنة في المنظمة والتي تتضمن

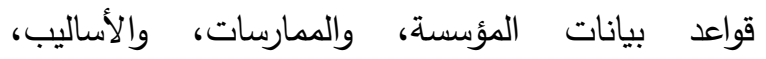

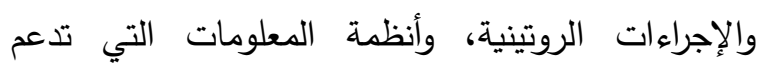
الموظفين في إكمال مهامهم، ويشمل جميع مخازن المعرفة غير البشرية في المنظمات مثل قواعد البيانات، وأدلة العمليات، والروتين، والاستراتيجيات، وينظم رأس لئرئ

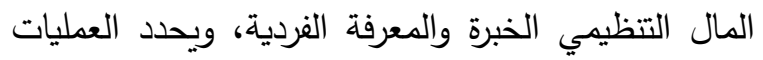
التجارية وأنظمة المعلومات، ويسمح بالتشغيل الفعال للمؤسسة، مما يساعد على التكيف مع المواقف الجديدة. - رأس المال الإجتماعي Social Capital ويسمى أيضًا رأس مال العلاقات Relational Capital: ويمثل قدرة المنظمة ذلى التواصل مع مختلف أصحاب المصلحة، بما في ذلك الموظفين أو العملاء أو الموردين أو الثركاء، ويعرّف على أنه الموارد الفعلية والمحتملة المضمنة في

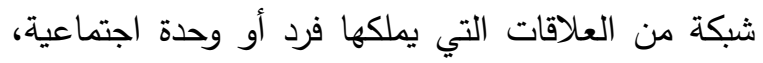
لذلك، تعد شبكات علاقات للشركة أو المنظمة، بما فيها شبكة العلاقات التي يمكن للمنظمة وأعضاؤها تأسيسها داخل بيئة العمل وخارجها والأصول المحتملة التي يتم الحصول عليها من خلال الثبكة مكونات أساسية لرأس وله

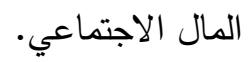

ويعتبر رأس المال الفكري كأصل غير ملمس مساوٍ في الفائدة إن لم يكن أكبر من الأصول الملموسة لخلق قيمة للمنظمة، كما يمكن إعتباره الحلقة بين إدارة الأصول غير لاصنول

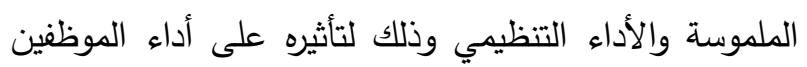

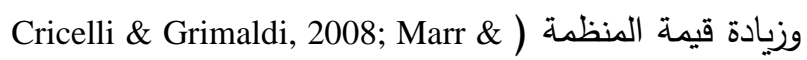
Sander, 2004, Wang, et al., 2015 فكرة رأس المال الفكري ظهور حقل إداري جديد سمي بإدارة
المزارع فقد ظهرت المنظمات العامة والخاصة لتزويد المزارعين بالمعارف والمعلومات، مما دعا إلى ظهور إدارة المعرفة بشكل بارز في معظم الاستراتيجيات لتعزيز التمية الزراعية (World Bank, 2007). ومن الضروري إعتماد نظام إرشاي يستخدم مصادر

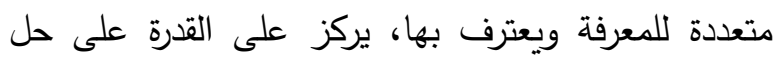

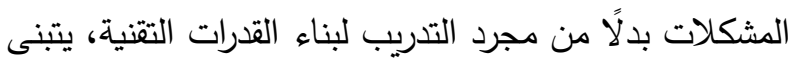
الاتصال التفاعلي والتعلم بالمشاركة، ويؤمن بالتعددية المؤسسية (Anandajayasekeram et.al., 2008). وفي هذه الحالة يلعب الإرشاد الزراعي كمدر للمعرفة دورًا محوريًا خصوصًا للزراع الذين يهتمون بممارسات الزراعة المستدامة والنظم الزراعية المستحدثة (Charatsari et al., 2009). ويعتبر رأس المال الفكري أحد المحركات الرئيسية للميزة التتافسية المستدامة لمنظمات الإرشاد الزراعي من حيث أنه يساهم في تحسين الأداء ) Stahle \& Hong, 2002; Roos et (al., 2005; Tayles et al., 2007 وضروري لقدرة المنظمة على البقاء وقوتها التنافسية .(Draghici, 2013) ويعرف رأس المال الفكري على أنه المادة الفكرية بما في ذلك المعرفة والمعلومات والملكية الفكرية والخبرة والعلامة التجارية والسمعة وثقافة المنظمة وما إلى ذلك، والتي يمكن Stewart, 1997; Low \& Kalafut, ) استخدامها لتكوين الثروة ومهله 2002)، ويشرح (1999) Bontis مفهوم رأس المال الفكري من خلال مناقشة كيفية دمج المعرفة الجماعية في الموارد البشرية والعمليات التظظيمية وشبكة العلاقات.

ويتكون رأس المال الفكري من مزيج من ثلاثة أنواع من رؤوس الأموال هي ( Bontis et al., 2000; Riahi-Belkaoui, 2003; Longo \& Mura, 2010; Shahpasand, et al., 2013;

:(Wang, et al., 2015 - - رأس المال البشري Human Capital: هو أهم أشكال رأس المال الفكري لأنه مصدر الثكلين الآخرين لرأس المال (رأس المال التظظيمي ورأس المال الاجتماعي)، ويضم 
أحمد محمد دياب وهند مختار دياب.: أثر رأس المال الفكري على الأداء الفردي وإدارة المعرفة بين خبراء الإرشاد الزراعي.... 481

(Knapp, 1998) ، أو هي العملية التي تخلق، وتثارك، Clemmons, 2002; ) وتوزع وتستخدم المعرفة في المنظمة Darroch, 2003 والأدوات والسلوكيات التي يشترك في صياغتها وأدائها المستفيدون من المنظمة، لإكتساب وخزن وتوزيع المعرفة لتتعكس على عمليات الأعمال للوصول إلى أفضل التطبيقات بقصد المنافسة طويلة الأمد (الكبيسي، 0 . . r) فإدارة المعرفة تعتبر نهجًا متكاملًا لتحديد وإدارة ومشاركة أصول المعلومات، بما في ذلك قواعد البيانات والسياسات والإجراءات بالإضافة إلى الخبرات والتجارب الثخصية الموجودة لدى الأفراد العاملين، ويستخدم مصطلح إدارة Ponelis \& Fairer-Wessels, 1998; De ) المعرفة للتمييز بين (Jager, 1999 ) ( ) إدارة المحتوى أو إدارة المعرفة: عملية إنثاء ومشاركة واستخدام وإدارة المعرفة والمعلومات الخاصة بالمنظمة، ويشير إلى نهج متعدد التخصصات لتحقيق الأهداف التتظيمية من خلال الاستفادة المثلى من المعرفة، لهيل وr) إدارة السجلات: إدارة المعلومات بالمنظمة خلال دورة حياتها من وقت الإنشاء والإستلام وحتى التخلص منها، وب) إدارة المعلومات: الحصول على المعلومات من مصدر واحد أو أكثر، والوصاية على تلك المعلومات وتوزيعها على من يحتاجونها، والتصرف النهائي بها من خلال الأشفة أو الحذف.

وتعتبر إدارة المعرفة - وخصوصًا في الإرشاد الزراعي أحد العوامل المهمة للتمية الزراعية، وتلعب استراتيجيات إدارة المعرفة دورًا مهمًا في التتمية الزراعية، وتعتبر إدارة المعرفة

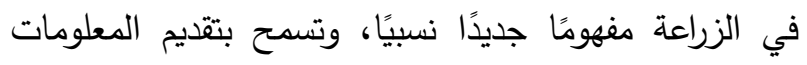
الصحيحة في الوقت والسياق المناسبين إلى المزارعين المستهدفين، وتدور إدارة المعرفة حول تسهيل أقصى قدر من

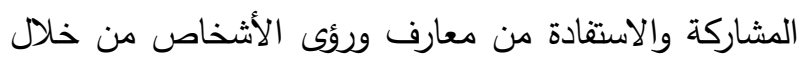
مشاركة المعرفة الضمنية في أذهان الأفراد من خلفيات وخبرات متتوعة (Kumar, et al., 2014).
المعرفة بغرض تحديد وإدارة ومشاركة أصول المعلومات، حrant, 1996; ) حيث أن المعرفة تتولد من رأس المال البشري .(Stewart, 2003

ولقد أظهرت الدراسات أن الموظفين يُظهرون أداءً فرديًا أفضل عندما يُسمح لهم بالتفكير والتصرف بإستقلالية، وعند Wang, et al., ) إمتلاكهم لمستوى جيد من رأس المال الفكري 2015)، وإذا استثرت المنظمات في تعليم موظفيها وتدربهم، فإن مهاراتهم المهنية وكفاءتهم ستزداد، مما يؤدي إلى زيادة Nerdrum \& Erikson, ) معدلات الأداء الفردي والتتظيمي 2001). ويشير كل من Mura \& Longo (2013) إلى أن أداء الأفراد داخل المنظمات يتضمن مؤشرات مثل الرضا الوظيفي (من حيث التقدير الذي يتلقاه الموظف نتيجة لأداءه، وفرص الترقي)، والالتزام التتظيمي (كالطريقة التي يتعامل بها الموظفون مع مصالح المنظمة)، والتوجه نحو ترك الوظيفة (فلكل موظف الحرية في ترك المنظملة والتخلي عنها بما لديه من خبرات وكفاءات ومعارف ضرورية لقيمة

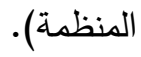

ومن جانب أخر ، ليس هناك شك في قيمة المعرفة والتعلم في تحسين كفاءة المنظمة، حيث أصبحت المعرفة أداة قوية للمنافسة (Shih et al., 2010)، فالمنظمات الناجحة لا تكتسب فوائد من خلال الأصول الملموسة فقط بل تعتمد بثكل أساسي على الوصول إلى المعلومات غير الملموسة وخلق المعرفة كمصادر رئيسية للنجاح (Guthrie, 2001) ، المعرفة المبل من أهم الموارد للمنظمة ما يستوجب العمل على حمايتها وتأهيلها وإدارتها (Kanigolzar, et al., 2013). وقد تم تقديم مصطلح إدارة المعرفة لأول مرة في مؤتمر الإدارة الأوروبي في عام 9 19، حيث يعرّف مركز الإنتاجية والجودة الأمريكية (APQC) إدارة المعرفة على أنها استراتيجيات وعمليات تحديد وتحصيل المعرفة والاستفادة منها (Atefeh et al., 1999)، وهي فن تحويل المعلومات والأصول الفكرية إلى قيمة دائمة لعملاء المؤسسات وأفرادها 


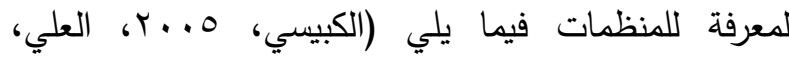

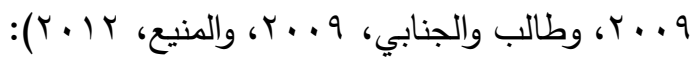
- تيسير العمميات وخفض التكاليف عن طريق تقليل كل من الإجراءات الزمن اللازم لتقديم الخدمات. - زيادة العائد المادي عن طريق تسويق المنتجات والخدمات بفعالية أكثر، وتطبيق المعرفة المتاحة واستخدامها في التحسين المستمر وابتكار منتجات وخدمات جديدة للحصول على الميزة التنافسية الدائمة. - ت تسيق أنشطة المؤسسة لتحقيق أهدافها، وتحفيزها على

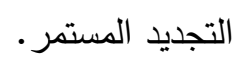

- إستثمار رأس المال الفكري للمؤسسة من خلال جعل الوصول إلى المعرفة المتولدة عنها بالنسبة للأشخاص الآخرين المحتاجين إليها عملية سهلة وممكنة. - دعم الجهود للاستفادة من جميع الموجودات الملموسة وغير الملموسة، بتوفير إطار عمل لتعزيز المعرفة وتوثيق المتوافر منها وتطويرها والمشاركة فيها وتطبيقها وتقييمها.

\section{المشكلة والأهداف البحثية}

من الإستعراض السابق يمكن القول بأن رأس المال الفكري (بمحاوره الثلاثة البشري، التظيمي، والإجتماعي) يخلق قيمة للمنظمة، ويشكل أداء الأفراد داخل تلك المنظمة (بمحاوره الثلاثة المتمثلة في الرضا الوظيفي، والالتزام التظيمي، والتوجه المنخفض نحو ترك الوظيفة)، كما أنه أيضًا أحد أهم موارد أو أصول في المنظمة التي تشكل إدارة المعرفة كأحد أهم الحلول لتحقيق النجاح، ولما كانت منظمات التعليم والإرشاد الزراعي من أهم المنظمات كثيفة المعرفة، تأتي هذه الدراسة لمحاولة دراسة تأثير رأس المال الفكري على كل من الأداء الفردي وإدارة المعرفة لدى خبراء الإرشاد الزراعي في الوطن العربي.
Andersen \& APQC, ) وتتكون أداة إدارة المعرفة من :(1996

The Knowledge Management عملية إدارة المعرفة Process المعرفة في عمليات إدارة وتتفيذ وتطوير عملياتها إضافة إلى أي مدى تستمر المنظمة في تقييم وتطوير عملياتها

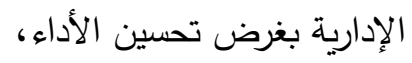

Leadership in Knowledge الريادة في إدارة المعرفة Management لتحديات إقتصاد المعرفة، وتهتم بسياسات وإستراتيجيات إدارة المعرفة في المنظمة من خلال قدرة المنظمة على ولى إستهلال وإرشاد وإستمرار ممارسات إدارة المعرفة، - كقافة إدارة المعرفة Knowledge Management Culture: وتركز على كيفية نظر المنظمة إلى كل من التعلم

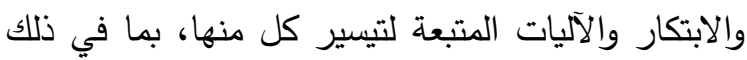
كيفية تشجيع الموظفين على بناء قاعدة المعرفة التتظيمية بطرق تعزز القيمة للمستهدفين، Knowledge Management تكنولوجيا إدارة المعرفة Technology معتمدة على المعرفة مثل نظم إدارة المحتوى والأدوات التشاركية ومدى واقعية وسهولة الاوصول إلى هذه الأدوات، التناركه

Knowledge Management قياس إدارة المعرفة Measurement المعرفي، بالإضافة إلى كيفية تخصيص الموارد اللازمة للنمو والتطور • ولم يعد خافيًا على الباحثين وقيادات المؤسسات أهمية إدارة المعرفة، ودورها في تطوير الخدمات والأعمال والارتقاء بأداء المؤسسات وتحقيق أهدافها بعوائد أفضل وتكاليف أقل، بل إن الالتزام بتطبيق مبادئ إدارة المعرفة أصبح من بن ضروريات البقاء للمؤسسات، ويمكن تلخيص أهمية إدارة 
أحمد محمد دياب وهند مختار دياب:: أثر رأس المال الفكري على الأداء الفردي وإدارة المعرفة بين خبراء الإرشاد الزراعي.... 483

والتي طورها (ICAT)

ثلاثة محاور رئيسية هي: رأس المال البشري Human Capital

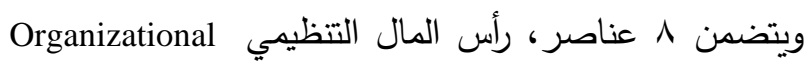
Social ويتضمن 10 capital capital المقياس r r عنصر • ويتم الإستجابة لتلك العناصر على مقياس ليكرت خماسي يتدرج من غير موافق مطلقًا ( () وغير موافق (Y)، ومحايد أو متوسط (Y)، موافق (ع)، موافق جدًا (0)، وبذلك يصبح إجمالي درجات المقياس ، •ـا درجة. وللتأكد من ثبات المقياس تم حساب قيمة معامل الثبات (ألفا

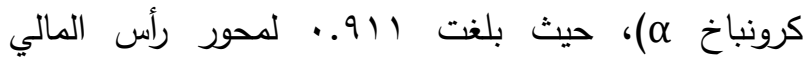

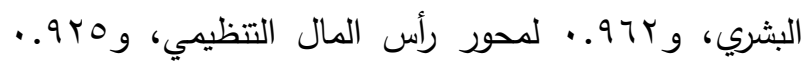
لمحور رأس المال الإجتماعي، وقد بلغت نحو 9 و . . لإجمالي رأس المال الفكري وجميعها قيم مقبولة إحصائيًا وتدل

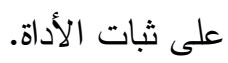
وتم قياس الأداء الفردي من خلال أداة قياس الأداء الفردي (Mura \& Longo, 2013) والتي تتضمن · م عناصر

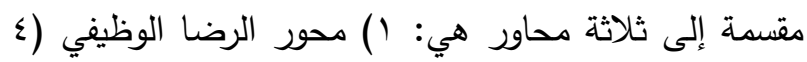

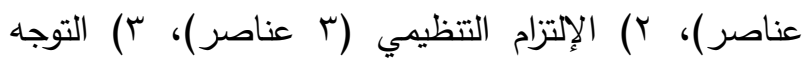
المنخفض نحو ترك الوظيفة (r عناصر) ويتم الإستجابة لتلك الك العناصر على مقياس ليكرت خماسي يتدرج من غير موافق

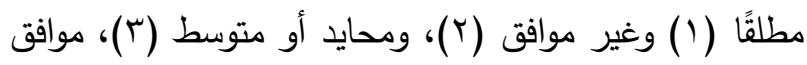
(ع)، موافق جدًا (0) والعكس للعبارات السلبية، وبذلك يصبح إجمالي درجات المقياس • درجة، وللتأكد من ثبات أداة قياس الأداء الفردي، تم حساب قيمة معامل الثبات (ألفا

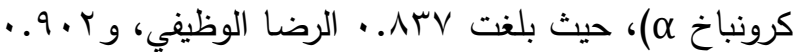

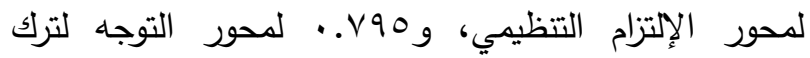
الوظيفة، وقد بلغت نحو هبر. . لإجمالي مقياس الأداء الفردي وجميعها قيمًا مقبولةً إحصائيًا وتدل على ثبات الأداة. وتم قياس إدارة المعرفة إعتمادًا أداة تقييم إدارة المعرفة Knowledge Management Assessment Tool (KMAT)

$$
\text { يهدف البحث الحالي إلى: }
$$

ا. قياس رأس المالي الفكري بين المبحوثين من خبراء الإرشاد الزراعي في الوطن العربي بإستخدام أداة تقييم

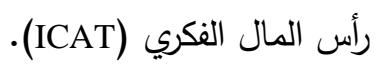

r. قياس الأداء الفردي لخبراء الإرشاد الزراعي في الوطن

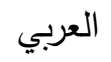

r. قياس إدارة المعرفة بين المبحوثين من خبراء الإرشاد الزراعي في الوطن العربي بإستخدام أداة تقييم إدارة

المعرفة (KMAT)

ء. تحديد أثر رأس المال الفكري على أداء خبراء الإرشاد

$$
\text { الزراعي في الوطن العربي }
$$

๑. تحديد أثر رأس المال الفكري على إدارة المعرفة بين خبراء

$$
\text { الإرشاد الزراعي في الوطن العربي }
$$

\section{الطريقة البحثية}

عينة الدراسة وأداة جمع البيانات

لتحقيق الغرض من البحث تم إستهداف خبراء الإرشاد

الزراعي العاملين في الجامعات والمراكز البحثية والوزارات المعنية في الوطن العربي المنضمين لمجموعة "ملتقى خبراء WhatsApp الإرشاد العرب" على تطبيق واتساب https://chat.whatsapp.com/DnyGbbvNowODIG4fkUJF

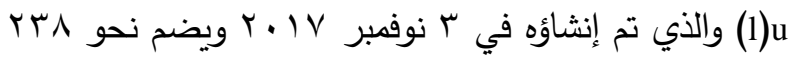
عضوًا من مختلف البلدان العربية (عينة غير إحتمالية)، من خلال إستمارة إستبيان إلكترونية صُمدت لتحقيق أهداف

$$
\text { الدراسة. }
$$

وبنشر رابط الإستبيان بالمجموعة المشار إليها خلال شهر يناير (Y.Y.T، تم تلقي الإستجابة من عدد •و خبير يمثلون V دول عربية هي (وفق الترتيب الأبجدي) الأردن،

والسعودية، والسودان، والعراق، واليمن، وسوريا، ومصر •

\section{القياس الرقمي لمتغيرات الدراسة}

لقد تم قياس رأس المال الفكري إعتمادًا على أداة قياس رأس المال الفكري Intellectual Capital Assessment Tool 
تحقيقًا للهذف الرابع للدراسة تم صياغة أربعة فروض أنقان

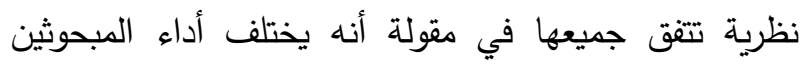

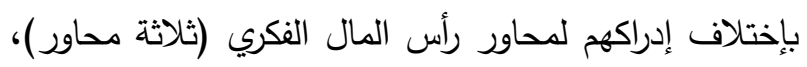

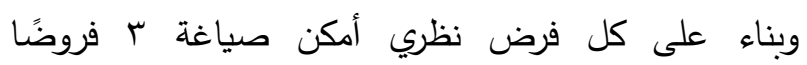

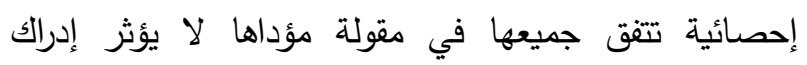

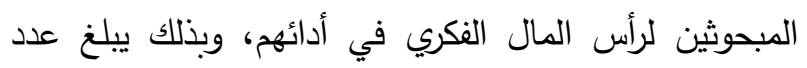

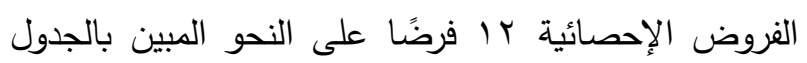

وتحقيقًا للهدف الخامس للدراسة تم صياغة ستة فروض

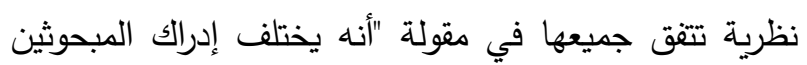
لكحاور إدارة المعرفة (خمسة محاور بالإضافة إلى الإجمالي)

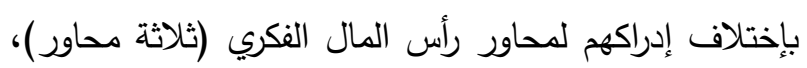
وبناء على كل فرض نظري أمكن صياغة ب فروضًا

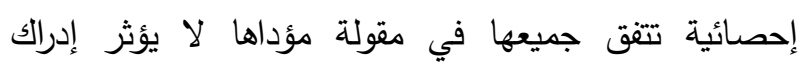

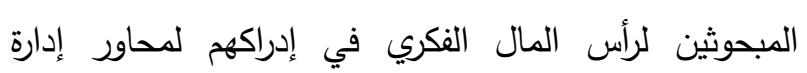

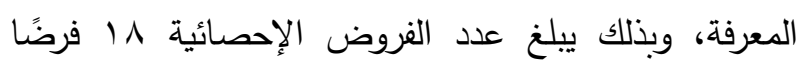
على النحو المبين بالجدول رقم (r).
والتي طورها (Andersen \& APQC, 1996)، وتتضمنت الأداة عدد ؟Y عنصر مقسمة على خمسة محاور للإدارة المعرفة هي: عملية إدارة المعرفة (0 عناصر)، القيادة في إدارة

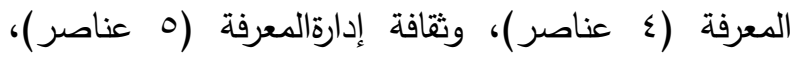

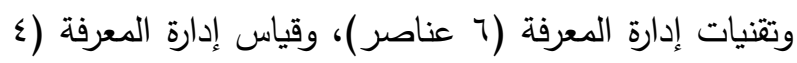

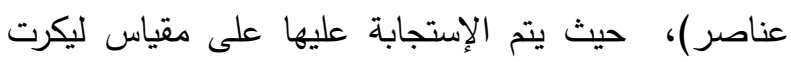

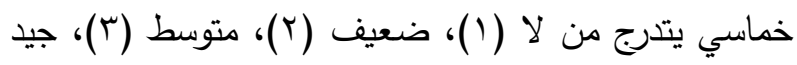

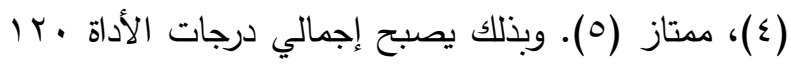

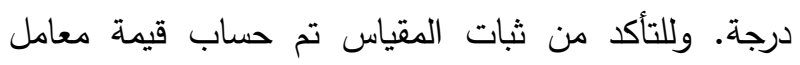

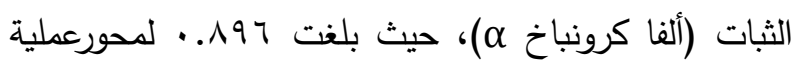

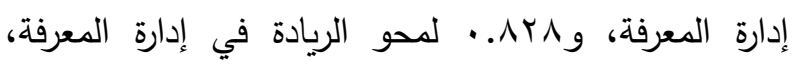

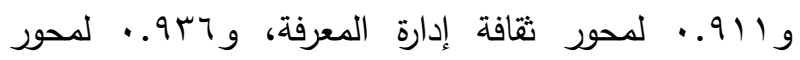

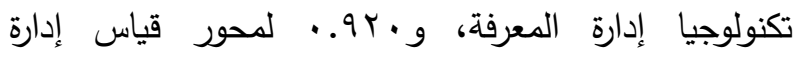

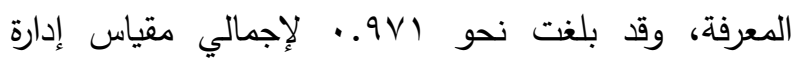

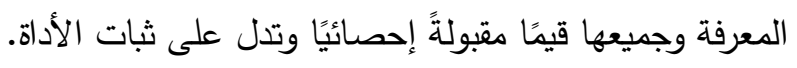

\section{الفروض البحثية}

جدول اــ مصفوفة الفروض الإحصائية للهدف الرابع (أثر رأس المال الفكري على أداة الأفراد)

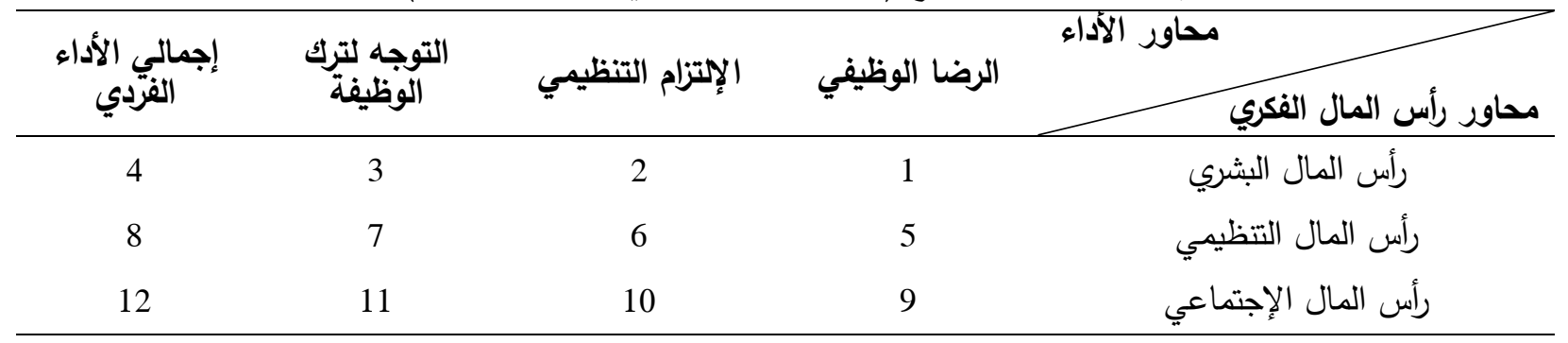

جدول ז. مصفوفة الفروض الإحصائية للهاف الخامس (أثر رأس المال الفكري على إدارة المعرفة)

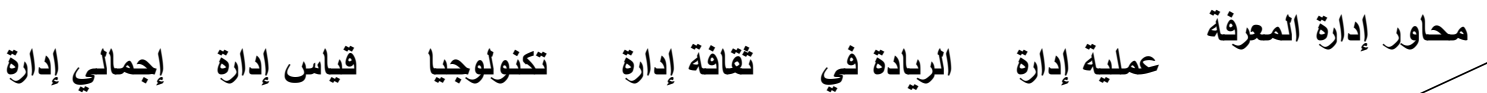
المعرفة إدارة المعرفة المعرفة إدارة المعرفة المعرفة المعرفة محاور رأس المال الفكري

\begin{tabular}{|c|c|c|c|c|c|c|}
\hline 18 & 17 & 16 & 15 & 14 & 13 & رأس المال البشري \\
\hline 24 & 23 & 22 & 21 & 20 & 19 & رأس المال التتظيمي \\
\hline 30 & 29 & 28 & 27 & 26 & 25 & رأس المال الإجتماعي \\
\hline
\end{tabular}


أحمد محمد دياب وهند مختار دياب:: أثر رأس المال الفكري على الأداء الفردي وإدارة المعرفة بين خبراء الإرشاد الزراعي..... 485

المبحوثين مصريين (r.بrه\%)، أعمارهم من · • سنة فأكبر

التحليل الإحصائي

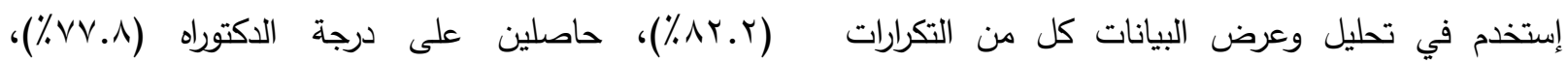

والنسب المئوية والمتوسط الحسابي والمدى ومعامل الثبات ومتخصصين في مجال الإششاد الزراعي (9.4\%)، وقد

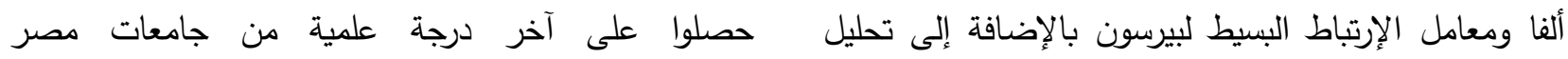

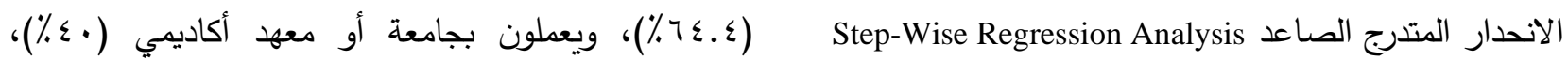
ولديهم من الخبرة بوظائفهم الحالية من · • أن سنوات فأكثر

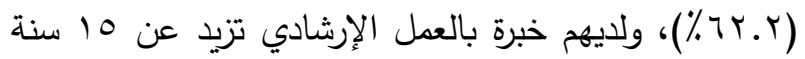

\section{النتائج ومناقشتها}

ا ـ وصف عينة الاراسة

تشير النتائج الواردة بالجدول رقم (ب) إلى أن غالبيــــة

\begin{tabular}{|c|c|c|c|c|c|}
\hline$\%$ & عدد & المتغير & $\%$ & عدد & المتغير \\
\hline & & دولة الحصول على آخر مؤهل & & & الجنسية \\
\hline 13.33 & 12 & الأردن & 22.22 & 20 & الأردن \\
\hline 4.44 & 4 & السودان & 6.67 & 6 & السعودية \\
\hline 2.22 & 2 & العراق & 4.44 & 4 & السودان \\
\hline 2.22 & 2 & اليمن & 8.89 & 8 & العراق \\
\hline 4.44 & 4 & 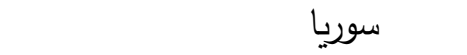 & 2.22 & 2 & 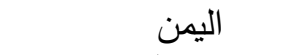 \\
\hline 64.44 & 58 & مصر & 2.22 & 2 & سوريا \\
\hline \multirow[t]{2}{*}{8.89} & 8 & ل & 53.33 & 48 & مصر \\
\hline & & جهة العمل ج & & & عمر المبحوث \\
\hline 40.00 & 36 & جامعة أو معهد أكاديمي & 17.78 & 16 & -30 \\
\hline 33.30 & 30 & مركز آو معهد بحثي & 40.00 & 36 & -40 \\
\hline 22.20 & 20 & قطاع تتفيذي بوزارة آلزراعة & 35.56 & 32 & -50 \\
\hline \multirow[t]{2}{*}{4.40} & 4 & آخرى & 6.67 & 6 & ( ) 60 سنة فآكثر \\
\hline & & عدد سنوات العمل بالوظيفة الحالية & & & المؤهل الدراسي \\
\hline 37.78 & 34 & آقل من 10 سنوات & 13.33 & 12 & مؤهل جامعي \\
\hline 31.11 & 28 & -10 & 8.89 & 8 & ماجستير \\
\hline \multirow[t]{2}{*}{31.11} & 28 & 20 سنة فأكثر & 77.78 & 70 & ل \\
\hline & & عدد سنوات الخبرة بالإرشاد الزراعى & & & التخصص \\
\hline 8.89 & 8 & أقل من 5 سنوات & 68.89 & 62 & إرشاد زراعي \\
\hline 13.33 & 12 & -5 & 8.89 & 8 & تتمية ريفية" \\
\hline 13.33 & 12 & -10 & 13.33 & 12 & إنتاج نباتي \\
\hline 22.22 & 20 & -15 & 4.44 & 4 & أراضي وميّاه \\
\hline 42.22 & 38 & 20 سنة فآكثر & 4.44 & 4 & إنتاج حيواني \\
\hline
\end{tabular}


النسب المئوية لمتوسطات كل المحاور منسوبة لأكبر درجة

$$
\text { لكل محور على حدة. }
$$

r. الأداء الفردي لخبراء الإرشاد الزراعي في الوطن العربي

تبين النتائج الواردة بالجدول (0) التوزيع العددي والنسبي

لمتوسطات إدراكات خبراء الإرشاد الزراعي في الوطن العربي محاور أداة تقييم الأداء الفردي، حيث بلغت قيمة المتوسط الحسابي لإجمالي الأداء الفردي للمبحوثين ه.Av

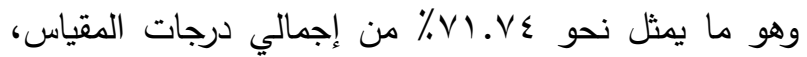
كما تشير نتائج الواردة بنفس الجدول إلى حصول محور

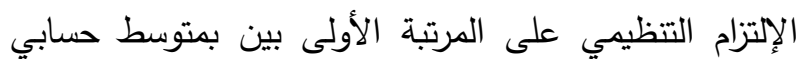

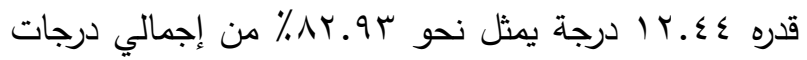
هذا المحور، يليه في الترتيب محور الرضا الوظيفي (0r.マ\% من إجمالي درجات المحور)، ثم محور التوجه لترك الوظيفة ( •عـ ــ ٪ من إجمالي درجات المحور). أما فيما يتعلق بتوزيع المبحوثين على الفئات الخاصة بالأداء الفردي، تثير النتائج الواردة بنفس الجدول إلى وقوع غالبية المبحوثين في الفئة المرتفعة لكل من الرضا الوظيفي

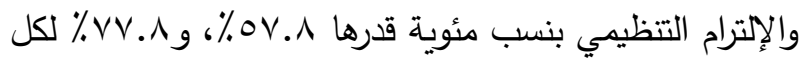
منها على الترتيب، في حين وقع غالبية المبحوثين في الفئة المتوسطة لكل من التوجه نحو ترك الوظيفة وإجمالي الأداء

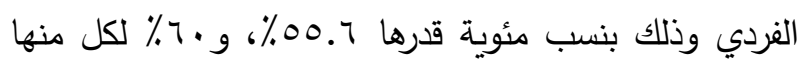
على الترتيب. r. رأس المال الفكري لاى خبراء الإرشاد الزراعي في الوطن العربي تبين النتائج الواردة بالجدول (ع التوزيع العددي والنسبي لمتوسطات إدراكات خبراء الإرشاد الزراعي في الوطن العربي

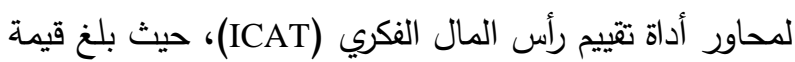
المتوسط الحسابي لإجمالي رأس المال الفكري من وجهة نظر

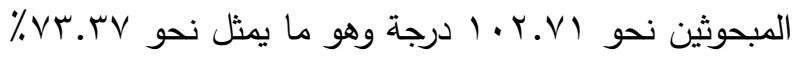
من إجمالي درجات المقياس، كما تثير نتائج الواردة بنفس الجدول إلى حصول محور رأس المال البشري على المرتبة الأولى بين محاور رأس المال الفكري بمتوسط حسابي قدره

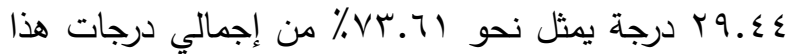
المحور، يليه في الترتيب محور رأس المال التظيمي (r من إجمالي درجات المحور)، ثم رأس المال

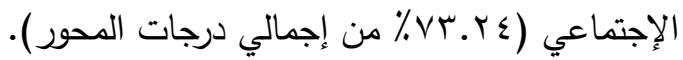
وفيما يتعلق بتوزيع المبحوثين على فئات رأس المال الفكري، تشير بيانات نفس الجدول إلى وقوع غالبية المبحوثين في الفئتين المتوسطة والمرتفعة وفقًا لكل محاور رأس المال الفكري، وبخصوص إجمالي رأس المال الفكري فقد وقع غالبية المبحوثين (1\%) في الفئة المرتفعة ونحو ؟ ٪ ٪ منهم في الفئة المتوسطة، اما الفئة المنخقضة فقط وقع فيها فقط ع.ء \% من المبحوثين، وهو ما يدلل على إرتقاع

جدول ع. التوزيع العددي والنسبي لمتوسطات إدراك خبراء الإرشاد الزراعي في الوطن العربي لمحاور أداة تقييم رأس المال الفكري

\begin{tabular}{|c|c|c|c|c|c|c|c|c|c|c|}
\hline \multicolumn{2}{|c|}{ الفئة المرتفعة } & \multicolumn{2}{|c|}{ الفئة المتوسطة } & \multicolumn{2}{|c|}{ المنخفضئة } & \multicolumn{2}{|c|}{ المتوسط الحسابي } & \multicolumn{2}{|c|}{ المدى } & \multirow{2}{*}{ محاور أداة تقييم رأس الفكري } \\
\hline$\%$ & عدد & $\%$ & عدد & $\%$ & عدد & $\%$ & قيمة & قيمة & قَّقة & \\
\hline 46.67 & 42 & 46.67 & 42 & 6.67 & 6 & 73.61 & 29.44 & 40 & 8 & رأس المال البشري \\
\hline 46.67 & 42 & 46.67 & 42 & 6.67 & 6 & 73.27 & 54.96 & 75 & 15 & رأس المال التظظيمى \\
\hline 53.33 & 48 & 37.78 & 34 & 8.89 & 8 & 73.24 & 18.31 & 25 & 5 & رأس المال الإجتمأعى \\
\hline 51.11 & 46 & 44.44 & 40 & 4.44 & 4 & 73.37 & 102.71 & 140 & 28 & إجمالى رأس المَّال الفكري \\
\hline
\end{tabular}


أحمد محمد دياب وهند مختار دياب.: أثر رأس المال الفكري على الأداء الفردي وإدارة المعرفة بين خبراء الإرشاد الزراعي..... 487 جدول ه. التوزيع العددي والنسبي لإدراك خبراء الإرشاد الزراعي في الوطن العربي لمحاور أداة تقييم الأداء الفردي

\begin{tabular}{|c|c|c|c|c|c|c|c|c|c|c|}
\hline \multicolumn{2}{|c|}{ الفئة المرتفعة } & \multicolumn{2}{|c|}{ الفئة المتوسطة } & \multicolumn{2}{|c|}{ الفئة المنخفضة } & \multicolumn{2}{|c|}{ المتوسط الحسابي } & \multicolumn{2}{|c|}{ المدى } & \multirow[b]{2}{*}{ محاور الأداء الفردي } \\
\hline$\%$ & عدد & $\%$ & عدد & $\%$ & عدد & $\%$ & قيمة & قُمية & أقلة & \\
\hline 57.78 & 52 & 37.78 & 34 & 4. 44 & 4 & 76.35 & 15.27 & 20 & 4 & الرضـا الوظيفي \\
\hline 77.78 & 70 & 13.33 & 12 & 8.89 & 8 & 82.93 & 12.44 & 15 & 3 & الإلتز ام التنظيمي \\
\hline 11.11 & 10 & 55.56 & 50 & 33.33 & 30 & 54.40 & 8.16 & 15 & 3 & التوجه لترك الوظيفة \\
\hline 37.78 & 34 & 60.0 & 54 & 2.22 & 2 & 71.74 & 35.87 & 50 & 10 & إجمالي الأداء الفردي \\
\hline
\end{tabular}

إدارة المعرفة (T. ب7\%٪ من إجمالي درجات المحور)، ومحور

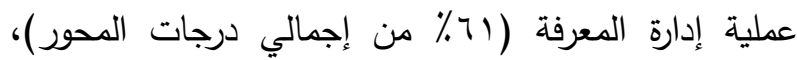

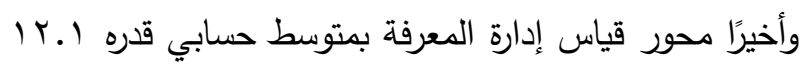

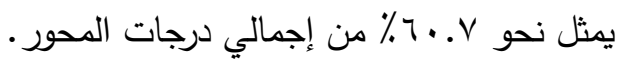
وفيما يتعلق بتوزيع المبحوثين على فئات إدارة المعرفة، تشير بيانات نفس الجدول إلى وقوع النسبة الأكبر من المبحوثين ضمن الفئة المتوسطة لجميع محاور أداة قياس إدارة المعرفة محل الدراسة، كما وقع ما يزيد عن نصف

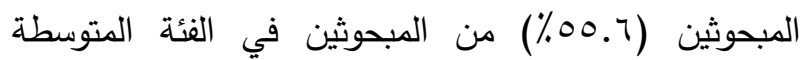
لإجمالي مقياس إدارة المعرفة في حين وقع ما يزيد قليًا عن

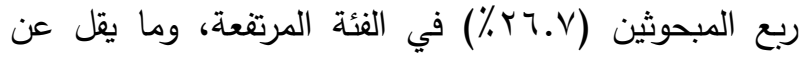

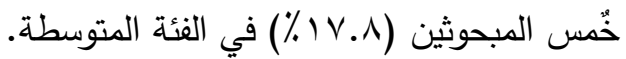

ع. إدارة المعرفة لاى خبراء الإرشاد الزراعي في الوطن العربي تبين النتائج الواردة بالجدول (†) التوزيع العددي والنسبي لمتوسطات إدراكات خبراء الإرشاد الزراعي في الوطن العربي لمحاور أداة تقييم إدارة المعرفة (KMAT)، حيث بلغ قيمة المتوسط الحسابي لإجمالي رأس إدارة العرفة من وجهة نظر

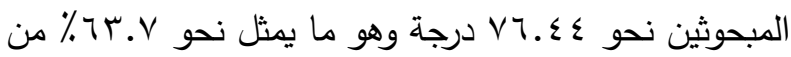
إجمالي درجات المقياس، كما تشير نتائج الواردة بنفس الجدول إلى حصول محور تكنولوجيا إدارة المعرفة على المرتبة الأولى بين محاور أداة إدارة المعرفة بمتوسط حسابي قدر 19.97 درجة يمثل نحو 7 .7\% من إجمالي درجات هذا المحور، يليه في الترتيب محور ثقافة إدارة المعرفة (7٪\% من إجمالي درجات المحور)، ثم محور الريادة في

جدول 1 ـ التوزيع العددي والنسبي لمتوسطات إدراك خبراء الإرشاد الزراعي في الوطن العزبي لمحاور أداة تقييم إدارة المعرفة

\begin{tabular}{|c|c|c|c|c|c|c|c|c|c|c|}
\hline \multicolumn{2}{|c|}{ المرتفعة } & \multicolumn{2}{|c|}{ المتوسطة } & \multicolumn{2}{|c|}{ المنخفضئة } & \multicolumn{2}{|c|}{ الحستابى المتيط } & \multicolumn{2}{|c|}{ المدى الم } & \multirow{2}{*}{ محاور أداة تقييم إدارة } \\
\hline$\%$ & عدد & $\%$ & عدد & $\%$ & عدد & $\%$ & قيمة & قيمبة & قيمة & \\
\hline 26.67 & 24 & 44.44 & 40 & 28.89 & 26 & 61.42 & 15.36 & 25 & 5 & عملية إدارة المعرفة \\
\hline 35.56 & 32 & 44.44 & 40 & 20.00 & 18 & 62.56 & 12.51 & 20 & 4 & الريادة فى إدارة المعرفة \\
\hline 31.11 & 28 & 51.11 & 46 & 17.78 & 16 & 65.96 & 16.49 & 25 & 5 & ثُقافة إدارة المعرفة \\
\hline 35.56 & 32 & 51.11 & 46 & 13.33 & 12 & 66.52 & 19.96 & 30 & 6 & تكنولوجياً إدارة المعرفة \\
\hline 31.11 & 28 & 42.22 & 38 & 26.67 & 24 & 60.67 & 12.13 & 20 & 4 & قياس إدارة المعرفة \\
\hline 26.67 & 24 & 55.56 & 50 & 17.78 & 16 & 63.70 & 76.44 & 120 & 24 & إجمالى إدارة المعرفة \\
\hline
\end{tabular}


الفروض الإحصائية (من / إلى Y I) التي تتص على عدم

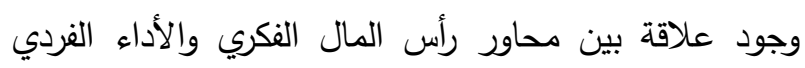
للمبحوثين من خبراء الإرشاد الزراعي في الوطن العربي.

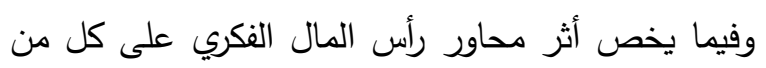
الرضا الوظيفي للمبحوثين والتوجه لترك الوظيفة المئة والإرتداد

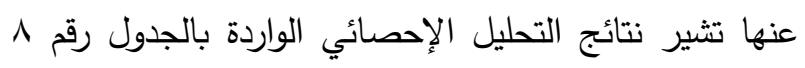
إلى معنوية النموذج الإحصائي عند الخطوة الأولى حيث الأنى

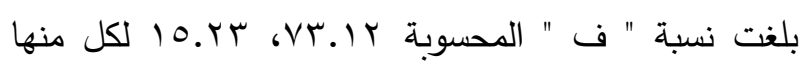

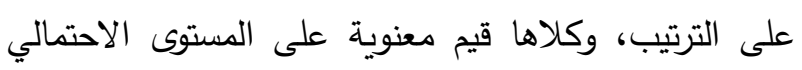

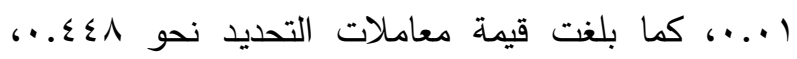

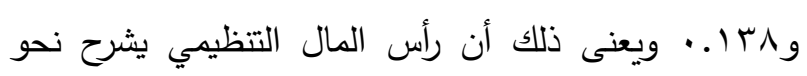

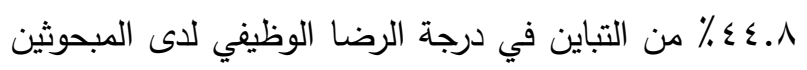

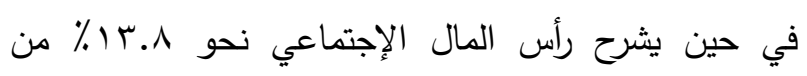
التباين الكلي في درجة توجه المبحوثين لترك الوظيف الإتيف

$$
\text { والإرتداد عنها. }
$$

وفيما يتعلق بأثر محاور رأس المال الفكري على الإلتزام

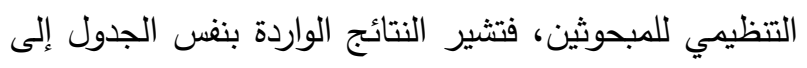

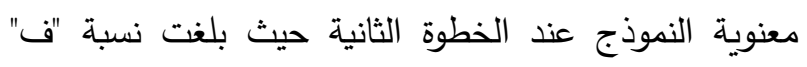

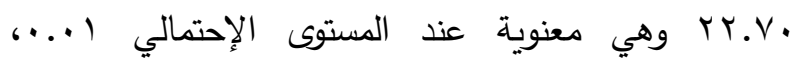
وبالنظر إلى قيم معامل التحديد، نجد أن كل من رأس المال الإلى

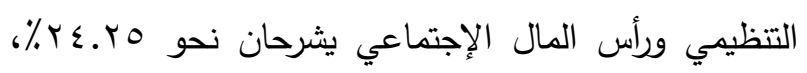

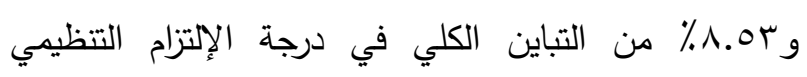

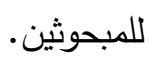

ه. أثر رأس المال الفكري على معدلات الأداء لاى خبراء الإرشاد الزراعي في الوطن العربي المبي

اختص الهدف الرابع بتحديد العلاقة بين الدرجة المعبرة

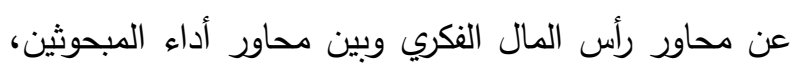

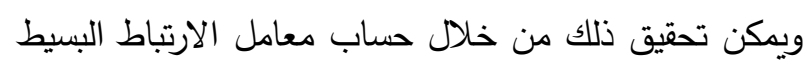

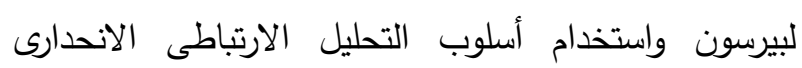

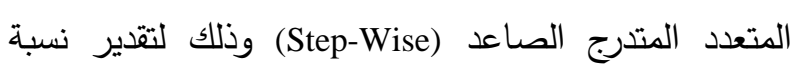
مساهمة كل من المتغيرات المستقلة المدروسة في التباين

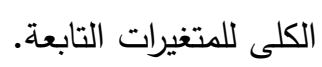

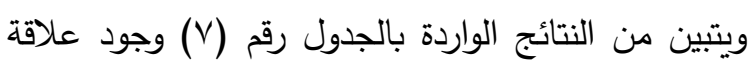

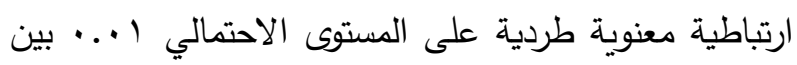
الدرجات المعبرة عن محاور الرضا الوظيفي لإلئي والإلتزام

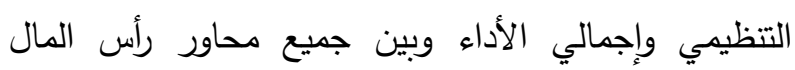

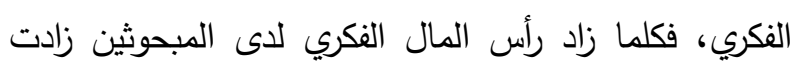

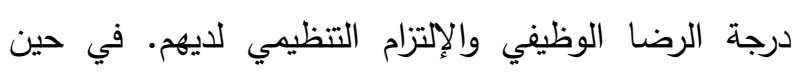

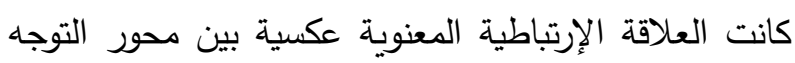

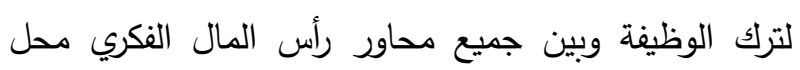

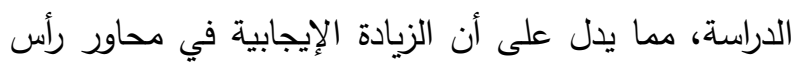

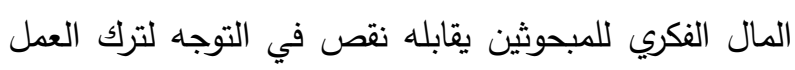
بالوظيفة الحالية.

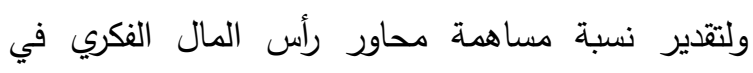

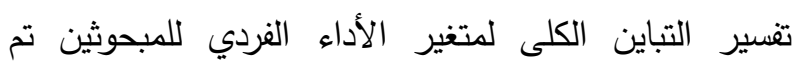
Step- استخدام أسلوب تحليل الانحدار المتدرج الصاعين Wise Regression Analysis

جدول V. قيم معامل الإرتباط البسيط لبيرسون للعلاقة بين محاور رأس المال الفكري ومحاور أداء خبراء الإرشاد الزراعي في الوطن

\begin{tabular}{|c|c|c|c|c|}
\hline إجمالي الأداء & التوجيفة لترك & الإلتزام التنظيمي & الرضا الوظيفي & محاور رأس المال الفكري محاور إدارة المعرفة \\
\hline 0,497 & "0.253- & "0.476 & "0.530 & رأس المال البشري \\
\hline “0.574 & "0.320- & " 0.501 & "*0.674 & رأس المال التنظيمي \\
\hline " 0.407 & "0.384- & •"0.352 & •"0.604 & رأس المال الإجتماعى \\
\hline$" 0.544$ & "0.328- & " 0.487 & " 0.649 & إجمالى رأَس أُلْمال الفَكري \\
\hline
\end{tabular}


أحمد محمد دياب وهند مختار دياب.: أثر رأس المال الفكري على الأداء الفردي وإدارة المعرفة بين خبراء الإرشاد الزراعي..... 489

\begin{tabular}{|c|c|c|c|c|c|c|}
\hline " فببة " & 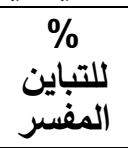 & التحديد & الإِتباط & المتغيرات المستقلة & خطوات التحليل & المتغيرات التابعة \\
\hline $73.121^{* * *}$ & 44.8 & 0.448 & 0.454 & رأس المال التتظيمي & 1 & الرضـا الوظيفي \\
\hline $29.490^{* * *}$ & 24.25 & 0.242 & 0.251 & رأس المال التتظيمي & 1 & الإلتزام التتظيمي \\
\hline $22.701^{* * *}$ & 8.53 & 0.328 & 0.343 & رأس المال الإجتماعي & 2 & \\
\hline $15.233^{* * *}$ & 13.79 & 0.138 & 0.148 & رأس المال الإجتماعي & 1 & التوجه لترك الوظيفة \\
\hline $43.141^{* * *}$ & 32.134 & 0.321 & 0.329 & رأس المال التتظيمي & 1 & إجمالي الأداء \\
\hline $34.648^{* *}$ & 10.923 & 0.431 & 0.443 & رأس المال الإجتماعي & 2 & \\
\hline
\end{tabular}

المعلومات التي تدعم الموظفين في إكمال مهامهم، ويسمح

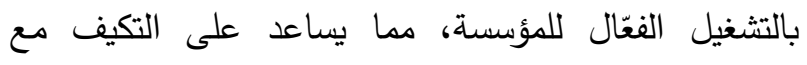
المواقف الجديدة.

أما رأس المال الإجتماعي والذي يثير للموارد الفعلية والمحتملة المضمنة في شبكة من العلاقات التي يملكها الفرد أو المنظمة بما فيها شبكة العلاقات الاجتماعية، فنجد أنه يسهم بنسب معنوية في تفسير التباين الكلي لكل من الإلتزام التظظيمي والتوجه لترك الوظيفة وإجمالي الأداء الفردي لئي للمبحوثين.

ج. أثر رأس المال الفكري على إدارة المعرفة بين خبراء الإرشاد الزراعي في الوطن العربي

اختص الهدف الخامس بتحديد العلاقة بين الدرجة المعبرة عن محاور رأس المال الفكري وبين محاور إدارة المعرفة محل الدراسة وذلك بحساب معامل الارتباط البسيط لبيرسون، وأسلوب التحليل الارتباطى الانحدارى المتعدد المتدرج الصاعد (Step-Wise) وذلك لتقدير نسبة مساهمة كل من المتغيرات المستقلة المدروسة في التباين الكلى للمتغيرات التابعة
أما فيما يتعلق بأثر محاور رأس المال الفكري على إجمالي أداء المبحوثين، تشير النتائج الواردة بنفس الجدول

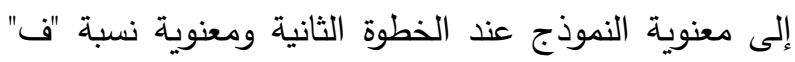
عند المستوى الإحتمالي ا +...، وبالنظر إلى قيم معامل التحديد، نجد أن كل من رأس المال التتظيمي ورأس المال

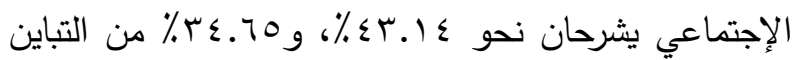
الكلي في درجة الأداء الفردي للمبحوثين. وبناء على النتائج السابقة يمكن للدراسة رفض الفروض

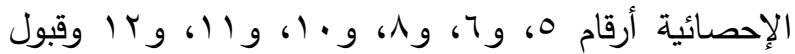
الفروض البديلة لها، في حين لم تتمكن الدراسة من رفض

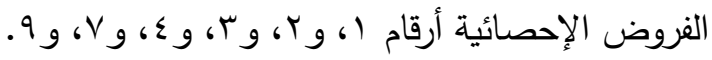
ولذا يمكن أن نخلص إلى أن رأس المال البشري لا يسهم بأي نسبة في تفسير التباين في أي محور من محورات أداء المبحوثين، في حين أن رأس المال التظظيمي يسهم بنسب معنوية في تفسير التباين في درجة الرضا الوظيفي ودرجة الإلتزام التظظيمي وإجمالي درجة الأداء للمبحوثين، ويمكن أن يكون ذلك بسبب أن رأس المال التظظيمي يثير إلى المعرفة المضمنة في المنظمة والتي تتضمن قواعد البيانات، والممارسات، والأساليب، والإجراءات الروتينية، وأنظمة 
كما تثير النتائج الواردة بنفس الجدول إلى معنوية

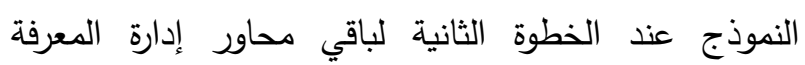

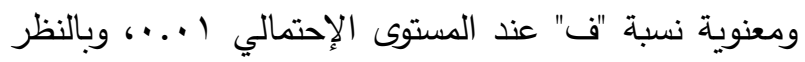

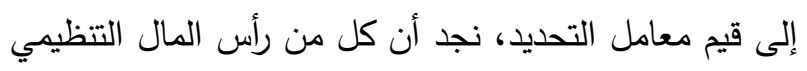

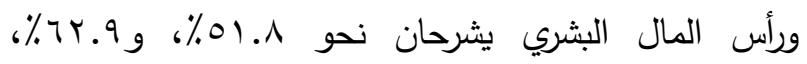

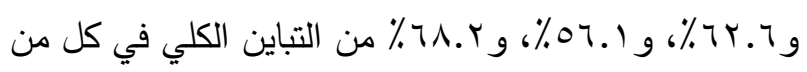

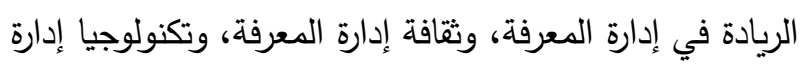

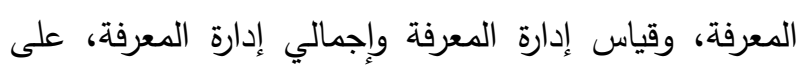

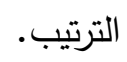

وبناء على ذللك يمكن للدراسة رفض الفروض الإحصائية

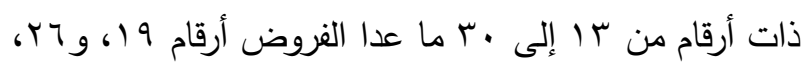

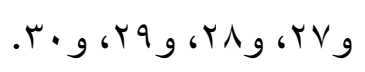

ونستخلص من النتائج السابقة أن كل من رأس المال

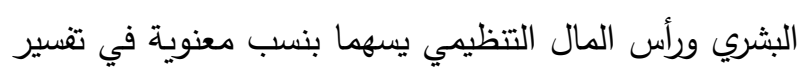

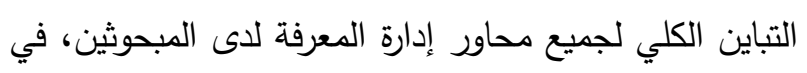

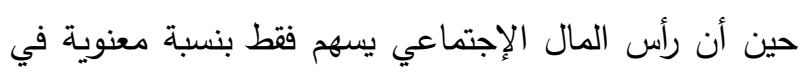

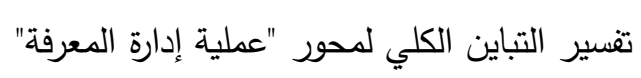

حيث يتبين من النتائج الواردة بالجدول رقم (9) أن هناك علاقة ارتباطية معنوية على المستوى الاحتمالي ال... بين

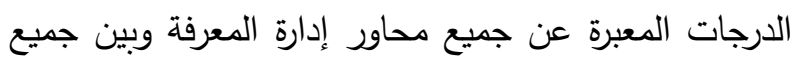

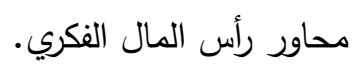
ولتتدير نسبة مساهمة محاور رأس المال الفكري في

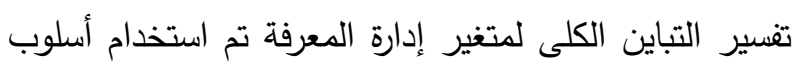

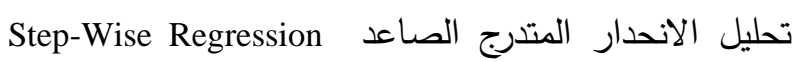
Analysis إلى •r) التي تتص على عدم تأثير محاور رأس المال

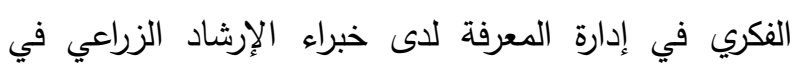

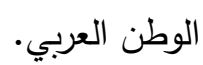
فيما يخص أثر محاور رأس المال الفكري على محور

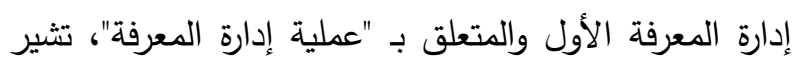

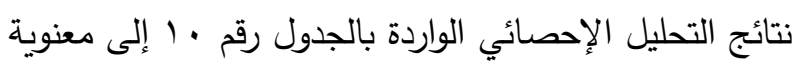

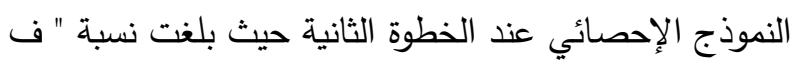

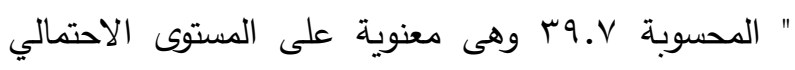

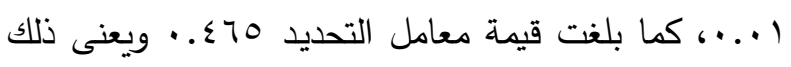
أن كل من رأس المال البشري ورأس المال الإجتماعي

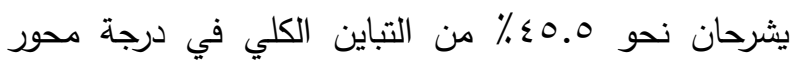
عملية إدارة المعرفة لدى المبحوثين.

جدول 9 ـ قيم معامل الإرتباط البسيط لبيرسون للعلاقة بين محاور رأس المال الفكري ومحاور إدارة المعرفة بين خبراء الإشاد

\begin{tabular}{|c|c|c|c|c|c|c|}
\hline إلجارة & قاس المعرفة إدارة & تكنولوجيا & ثقافة إدارة & الريادة في المعرة & علية إدارة & محاور إدارة المعرفة \\
\hline${ }^{* *} 0.788$ & $* * 717$ & ${ }^{* *} 0.760$ & ${ }^{* *} 0.738$ & ${ }^{* *} 0.690$ & ** 0.665 & رأس المال البشري \\
\hline ** 0.805 & ** 0.732 & **0.769 & ${ }^{* *} 0.786$ & ${ }^{* *} 0.705$ & ** 0.653 & رأس المال التنظيمي \\
\hline ** 0.757 & ** 0.665 & ${ }^{* *} 0.748$ & ** 0.727 & ${ }^{* *} 0.647$ & ** 0.626 & رأس المال الإجنماعي \\
\hline${ }^{* *} 0.828$ & ${ }^{* *} 0.748$ & ${ }^{* *} 0.798$ & ${ }^{* *} 0.796$ & ${ }^{* * *} 0.722$ & ${ }^{* * *} 0.681$ & إجمالي رأس المال الفكري \\
\hline
\end{tabular}


أحمد محمد دياب وهند مختار دياب.: أثر رأس المال الفكري على الأداء الفردي وإدارة المعرفة بين خبراء الإرشاد الزراعي.... 491

جدول رقم • 1 ـ نتائج الأثز التجميعي لإدراكات المبحوثين لمحاور رأس المال الفكري على محاور إدارة المعرفة

\begin{tabular}{|c|c|c|c|c|c|c|}
\hline " فببة " & \% للتباين & التحديد & معامل الإرتباط & المتغيرات المستقلة & خطوات & المتغيرات التابعة \\
\hline "69.68 & 43.6 & 0.436 & 0.442 & رأس المال البشري & 1 & عملية إدارة المعرفة \\
\hline$" 39.70$ & 2.9 & 0.465 & 0.477 & رأس المال الإجتماعي & 2 & \\
\hline "87.09 & 49.2 & 0.492 & 0.497 & رأس المال التتظيمي & 1 & الريادة في إدارة المعرفة \\
\hline "* 48.81 & 2.6 & 0.518 & 0.529 & رأس المال البشري & 2 & \\
\hline " 141.97 & 61.3 & 0.613 & 0.617 & رأس المال التنظيمى & 1 & ثقافة إدارة المعرفة \\
\hline "*76.42 & 1.6 & 0.629 & 0.637 & رأس المال البشري & 2 & \\
\hline$" 127.40$ & 58.7 & 0.587 & 0.591 & رأس المال التتظيمي & 1 & تكنولوجيا إدارة المعرفة \\
\hline "75.45 & 3.9 & 0.626 & 0.634 & رأس المال البشري & 2 & \\
\hline "* 101.42 & 53.0 & 0.530 & 0.535 & رأس المال التتظيمى & 1 & قياس إدارة المعرفة \\
\hline "“57.76 & 3.1 & 0.561 & 0.570 & رأس المال البشري & 2 & \\
\hline "*161.93 & 64.4 & 0.644 & 0.648 & رأس المال التنظيمى & 1 & إجمالى إدارة المعرفة \\
\hline " "96.53 & 3.8 & 0.682 & 0.689 & رأس المال البشري & 2 & \\
\hline
\end{tabular}

كل من رأس المال الإجتماعي ورأس المال التظيمي يسهما بنسب معنوية في تفسير التباين الكلي في مستوى أداء المبحوثين في حين يسهم كل من رأس المال البشري ورأس فئس فئسئ

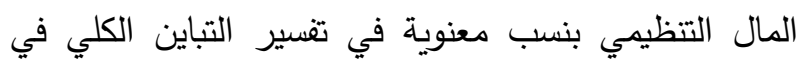
مستوى إدارة المعرفة بين خبراء الإرشاد الزراعي في الوطن العربي، كما خلصت الدراسة إلى إسهام رأس المال التظيمي

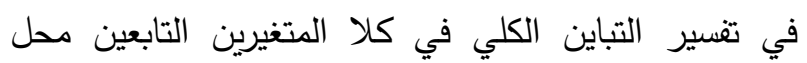

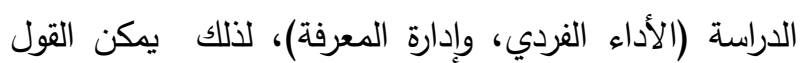
بأن التحسين في كل من رأس المال الإجتماعي والتنظيمي يسهم في تحسين أداء المبحوثين والتحسين في رأس المال البشري والتنظيمي يسهر في تحسين إدارة المعرفة بين المبحوثين، أما التحسين في رأس المال التتظيمي يمكن أن لن يسهر في تحسين كل من مستوى أداء المبحوثين ومستوى إدارة المعرفة لديهم.

وبناء على ما تم التحصل عليه من نتائج، فتوصي بما يلي: - إجراء المزيد من الدراسات التفصيلية لقياس كل من رأس

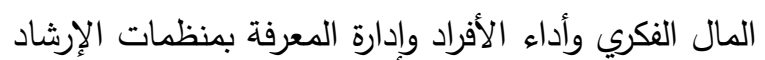

$$
\text { الزراعي في الوطن العربي. }
$$

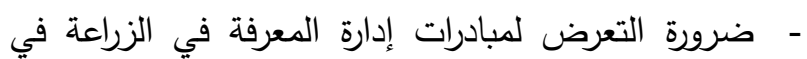
جميع أنحاء العالم، واكتساب المعلومات المباشرة

\section{الخلاصة والتوصيات}

بناءً على ما سبق، تعتبر المعرفة هي المصدر الرئيسي

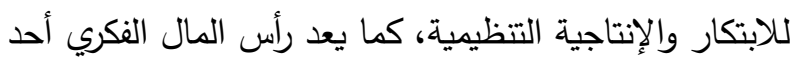
القدرات التنظيمية المهمة التي يمكن أن تساعد المنظمات على إنشاء المعرفة وإدارتها وأيضًا المنافسة المستدامة للآخرين، كما يمكنه أن يزيد من قدرة المنظمات على التطوير والإبداع والابتكار وتحسين الأداء داخل تلك يلك المنظمات.

وقد إستهدف البحث الحالي الكثف عن تأثير رأس المال الفكري على كل من مستوى الأداء الفردي وإدارة المعرفة بين خبراء الإرشاد الزراعي في الوطن العربي، وقد توصلت الدراسة إلى أن متوسط الدرجات التي حصل عليها المبحوثين وفقًا لكل من مقياس رأس المال الفكري ومقياس الأداء

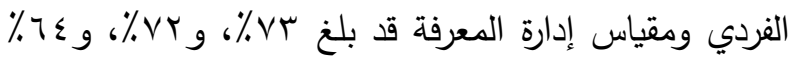
من جملة كل منها على الترتيب، وهي قيم مقبولة في كل من رأس المال الفكري والأداء الفردي وقليلة نسبيًا فيما يتعلق

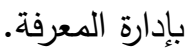

كما أظهر تحليل الارتباط وجود علاقة إرتباطية معنوية بين كل من مؤشرات رأس المال الفكري وأداء المبحوثين وإدارة المعرفة، بناء على نتائج الدراسة يمكن إستخلاص أن 
Bhatt, G., A. Emdad; N. Roberts \& V. Grover (2010), "Building and leveraging information in dynamic environments: the role of IT infrastructure flexibility as enabler of organizational responsiveness and competitive advantage", Information \& Management, 47(7/8): 341349.

Bontis, N. (1999). Managing an organizational learning system by aligning stocks and flows of knowledge: An empirical examination of intellectual capital, knowledge management and business performance. Ph.D. Dissertation, London, Canada: Ivey Business School, University of Western Ontario.

Bontis, N., W. Keow \& S. Richardson (2000). Intellectual capital and business performance in Malaysian industries. Journal of Intellectual Capital, 1, 85-100.

Charatsari, Ch.; A. Papadaki-Klavdianou, and A. Michailidis (2009) Comparing Information in Organic Farming, Conventional Agriculture and Integrated Crop Management. In Chiara Paffarini and Fabio Maria Santucci (2009). Theory and practice of advisory work in a time of turbulences, 19th European Seminar on Extension Education, Italy, pp 308-313.

Clemmons, R. M. (2002), The Complete Idiot's Guide to Knowledge Management, Pearson Education Company.

Cricelli, L., \& M. Grimaldi (2008). A dynamic view of knowledge and information: A stock and flow-based methodology. International Journal of Management and Decision Making, 9(6), 686-698.

Darroch, J. (2003), Developing a measure of knowledge management behaviors and practices. Journal of knowledge management, 7(5), 41-54.

De Jager, M. (1999) The KMAT: benchmarking knowledge management. Library Management, 20(7): 367-372.

Draghici, A. (2013). A possible approach for generic model concerning intellectual capital evaluation. Annual session of scientific papers IMT, 12: 267-273.

Gogan, Maria-Luminita (2014). An innovative model for measuring intellectual capital. Social and Behavioral Sciences, 124: $194-199$.

Grant, R. M. (1996). Towards a knowledge-based theory of the firm. Strategic Management Journal, 17(2), 108-122.

Guthrie, J. (2001)."The management, measurement and reporting of intellectual capital", Journal of Intellectual Capital, 2(1): 27-41.

Kanigolzar, F. M.; M. Savari \& N. Motee (2013). The effect of intellectual capital on knowledge management: study on agriculture organization experts in kurdistan province. Journal on Efficiency and Responsibility in Education and Science. 6(1): 14-23.

Knapp, E. M. (1998). Knowledge Management. Business and Economic Review, 44(4), 3-7.

Kumar, S A.; C. Shanker; P. Muthuraman; B Sailaja; V. R. Babu \& M. Shaik (2014). Agricultural knowledge management tools and processes: A case of rice knowledge management portal. $3^{\text {rd }}$ International Conference on Agriculture \& Horticulture. Hyderabad International Convention Centre, India.

$$
\begin{aligned}
& \text { والمهارات الإدارية كأحد مفاتيح استراتيجيات إدارة المعرفة }
\end{aligned}
$$

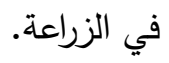

$$
\begin{aligned}
& \text { - العمل على تتمية رأس المال الفكري في المنظمات } \\
& \text { الزراعية بصفة عامة والإرشاد الزراعي بصفة خاصة } \\
& \text { وذلك لتأثيره الواضح على أداء العاملين وعملية إدارة }
\end{aligned}
$$

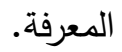$$
\text { - العمل على زيادة قدرة أجهزة الإرشاد الزراعي على }
$$$$
\text { الإحتفاظ بقدرات موظفيها وتطويرها وتتظيمها والاستفادة }
$$$$
\text { منها. }
$$$$
\text { المراجحم }
$$

$$
\begin{aligned}
& \text { العلي، عبدالستار (ج · . ب). المدخل الى إدارة المعرفة، دار } \\
& \text { المسيرة للنشر والتوزيع والطباعة، عمان } \\
& \text { الكبيسي، صلاح الدين (0. . (ب). إدارة المعرفة، المنظمة } \\
& \text { العربية للتمية الإدارية، جامعة الدول العربية. } \\
& \text { المنيع، محمد بن عبدالله (Y ( ا r). إدارة المعرفة وعلاقتها } \\
& \text { بتطوير الخطط والبرامج التعليمية في الجامعات السعودية } \\
& \text { نموذج مقترح، المجلة السعودية للتعليم العالي السعودي، } \\
& \text { عدد } 7 .
\end{aligned}
$$

$$
\begin{aligned}
& \text { طالب، علاء فرحان وأميرة الجنابي (9 . . †). إدارة المعرفة: } \\
& \text { إدارة معرفة الزبون، دار صفاء للنشر والتوزيع، عمان. }
\end{aligned}
$$

Allameh, S. M.; S. M. Zare and S. M. R. Davoodi (2010). Examining the Impact of KM Enablers on Knowledge Management Processes. Computer Science. 3: 1211-1223.

Anandajayasekeram, P., R. Puskur, S. Workneh and D. Hoekstra (2008). Concepts and practices in agricultural extension in developing countries: A source book. IFPRI (International Food Policy Research Institute), Washington, DC, USA, and ILRI (International Livestock Research Institute), Nairobi, Kenya.

Andersen, A. and The American Productivity and Quality Center (1996). The Knowledge Management Assessment Tool: External Benchmarking. APQC. USA.

Atefeh, S.; L.McCamble; C. Moorchead \& S. H. Gitters, (1999). Knowledge management: the new challenge for the 21 century. Journal of Knowledge Management, 3(3), 172-179. 
أحمد محمد دياب وهند مختار دياب:: أثر رأس المال الفكري على الأداء الفردي وإدارة المعرفة بين خبراء الإرشاد الزراعي.... 493

Roos, G., S. Pike and L. Fernstrom (2005) Managing Intellectual Capital in Practice, Burlington, MA: Elsevier Publications.

Shahpasand M.; M. Savari \& V. Sarani (2013). The Effect of Intellectual Capital on Knowledge Management: Study on Agriculture Organization Experts in Kurdistan Province. International Journal of Business and Social Science. 4(12): $321-327$

Shih, K. H.; Ch. J. Chnag; \& B. Lin (2010)."Assessing knowledge creation and intellectual capital in banking industry", Journal of Intellectual Capital, 11(1): 74-89.

Stewart, T. (1997). Intellectual capital: The new wealth of organizations. New York: Nicholas Brealey Publishing, Business Digest.

Stewart, T. (2003). The Wealth Knowledge: Intellectual Capital and the Twenty-First Century Organization. London: Nicholas Brealey.

Sthale, P. and J. Hong (2002). Dynamic intellectual capital in global rapidly changing industries, Journal of Knowledge Management, 6, 117-189.

Tayles, M., R.H. Pike and S. Sofian (2007) Intellectual capital, management accounting practices and corporate performance. Perceptions of managers, Accounting, Auditing \& Accountability Journal, 20, 522-548.

Wang, C.H.; C. D. Yen; G. H. W. Liu (2015). How intellectual capital influences individual performance: A multi-level perspective. Computers in Human Behavior 51 (2015) 930-937.

World Bank (2007). Enhancing Agricultural Innovation: How to Go Beyond the Strengthening of Research Systems. Washington, DC: World Bank.
Longo M. and M. Mura (2010). A methodology for measuring intellectual capital. A structural equations modelling approach. In Milind Sharma (ed) Advances in Measurement Systems. IntechOpen.

Low, J., \& Kalafut, P.C. (2002). Invisible Advantage - How Intangibles are Driving Business Performance, Perseus Publishing, and Cambridge.

Marr, B., \& J. C. Spender, (2004). Measuring knowledge assets - Implications of the knowledge economy for performance measurement. Measuring Business Excellence, 8(1), 18-27.

Mura, M. \& M. Longo (2013). Developing a tool for intellectual capital assessment: an individual-level perspective. Expert Systems. (30)5: 436-450.

Nerdrum, L., \& T. Erikson (2001). Intellectual capital: A human capital perspective. Journal of Intellectual Capital, $2,127-135$.

Ponelis, S. and F. A. Fairer-Wessels, (1998), “'Knowledge management: a literature overview", South African Journal of Library and Information Science, 66(1): 1-9.

Rajalahti, Riikka, Willem Janssen and Eija Pehu (2008). Agricultural Innovation Systems: From Diagnostics Toward Operational Practices. Agriculture and Rural Development Discussion Paper 38, World Bank, Washington, DC.

Riahi-Belkaoui, A. (2003). Intellectual capital and firm performance of US multinational firms. A study of the resource-based and stakeholder views. Journal of Intellectual Capital, 4, 215- 226.

\title{
ABSTRACT \\ The Effect of Intellectual Capital on the Individual Performance and Knowledge Management Among Experts of Agricultural Extension in the Arab World
}

\author{
Ahmed M. Diab , Hend M. Diab
}

The current research aims to: 1) measure the intellectual capital (IC) among agricultural extension experts in the Arab world using the Intellectual Capital Assessment Tool (ICAT), 2) measure individual performance of respondents, 3) measure knowledge management (KM) among respondents using the Knowledge Management Assessment Tool (KMAT), and 4) determine the impact of IC on the individual performance of respondents, and 5) determine the impact of IC on KM among agricultural extension experts in the Arab world. Data were collected through an electronic questionnaire form from 90 experts representing 7 Arab countries, which are Jordan, Saudi Arabia, Sudan, Iraq, Yemen, Syria, and Egypt, during January 2021. According to results of the study, the mean value of respondent' perceptions for IC, individual performance, and $\mathrm{KM}$ are $73.37 \%, 71.7 \%$, and $63.7 \%$ of the total scores, respectively. There is a significant correlation relationship at the probability level 0.01 between the scores expressing all dimensions of IC and all dimensions of the individual performance and KM. The results also indicate that both organizational and social capitals explain about $43.1 \%$ and $34.7 \%$ of the variance of respondents' individual performance, also, both organizational and human capitals explain about $68.2 \%$ of the total variance in total $\mathrm{KM}$, so that study could reject about 18 of the thirty statistical hypotheses. Finally, some conclusions and recommendation are provided.

Keywords: Intellectual capital, individual performance, knowledge management, agricultural extension, Arab world 